\title{
Linking spatial patterns of deforestation to land use using satellite and field data
}

\author{
Rodrigo B. Lorena ${ }^{1}$ \\ Eric F. Lambin ${ }^{1}$ \\ ${ }^{1}$ Université Catolique de Louvain - UCL \\ Place Louis Pasteur 3, 1348 Louvain-la-Neuve - Belgium \\ \{lorena, lambin\}@geog.ucl.ac.be
}

\begin{abstract}
The Brazilian Amazon is an area where extensive tropical rainforest areas are being converted to agriculture and cattle raising activities, contributing to environmental and landscape changes of this large region. The main objective of this paper is test whether spatial patterns of deforestation as visualized by satellite images are related to land use data as collected by household survey. This linkage would allow for a better understanding of the dynamic of land use and cover change at a regional scale. The results demonstrated the capacity of our methodology in quantifying and mapping deforestation patterns and to relate these patterns to land use activities at the household level.
\end{abstract}

\section{Introduction}

The Brazilian Amazon has been the target of human activities that have resulted in the largescale conversion of tropical forest into cropland and cattle ranching areas, thus contributing to the alteration of the natural environment and the Amazon landscape. The increasing human occupation of forest areas has caused significant changes in the ability of the environment to deliver key ecosystem goods and services. It also creates an uncertain future for the sustainability of the regional to global environment due to interconnections between natural processes in the Amazon and the regional and global climate. In order to evaluate the pattern of occupation of the Amazon region and its impacts on the environment, it is essential to establish a monitoring of land use and cover changes at a regional scale. The main objective of this paper is to test whether spatial patterns of deforestation as visualized by satellite images are related to land use data as collected by household survey. This linkage would allow for a better understanding of the dynamic of land use and cover change at a regional scale. It would also allow for a stratification of forest frontier areas in terms of processes of land use change, and thus would facilitate a finetuning of policies to the particular socio-economic dynamics underlying deforestation.

\section{Study area}

The study area (fig. 1), with a size of $3,744 \mathrm{Km}^{2}$, is located in the western Acre State, with the geographical coordinates S $9^{\circ} 38^{\prime}$ to $10^{\circ} 26^{\prime}$ and $\mathrm{W} 66^{\circ} 41^{\prime}$ to $67^{\circ} 30^{\prime}$. The main settlement of this area is Acrelândia. It is cut in the E-W direction by highway BR-364, connecting Rio Branco (AC) to Porto Velho (RO). This is an interesting area to test our methodology because it contains diverse occupation patterns, associated with a diversity of actors and different land use activities in a relatively small area with easy access. 


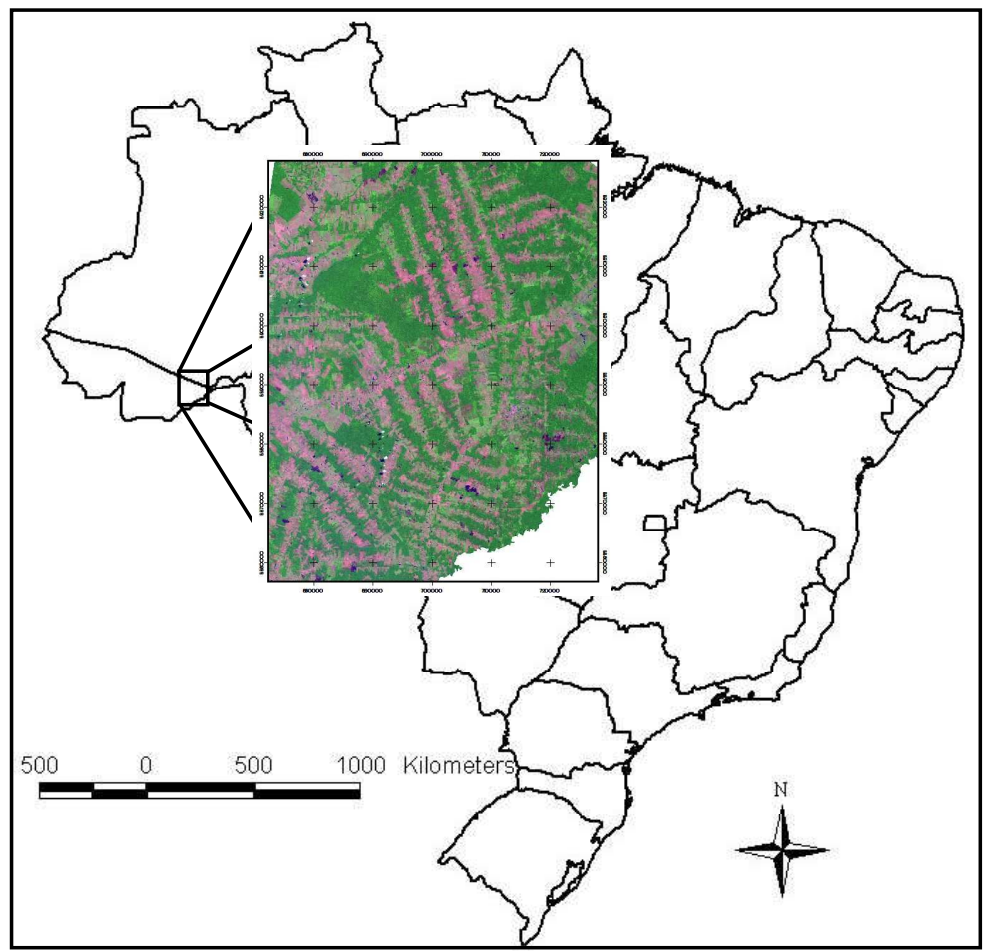

Figure 1 - Study area

\section{Material and method}

\subsection{Material}

This study was based on 12 Landsat-5 and 7 Thematic Mapper (TM) multispectral images (path and rwo 001/67), for the years 1990, 1991, 1994, 1995, 1996, 1997, 1998, 1999, 2001, 2002, 2003 and 2004. The images were processed using the free software SPRING, version 4.2. The field work benefited from logistic support from the National Institute for Colonization (INCRA). Data collected in the field were analyzed using the statistical software SAS.

\subsection{Method}

The first step of this study was the identification of different spatial patterns of deforestation. It was done using a methodology of photo interpretation (Veneziani, 1994), supported by an analysis of the history and the geometry of land use at the landscape scale. Figure 2 shows: (a) the deforestation patterns identified by photo interpretation and (b) a Landsat image with settlement plans overlaid. We also applied a supervised classification to separate forest from non forest, following the PRODES digital methodology (Duarte et al, 1999). This allowed mapping and quantification of deforestation for the entire area and for each spatial pattern of land use identified. 


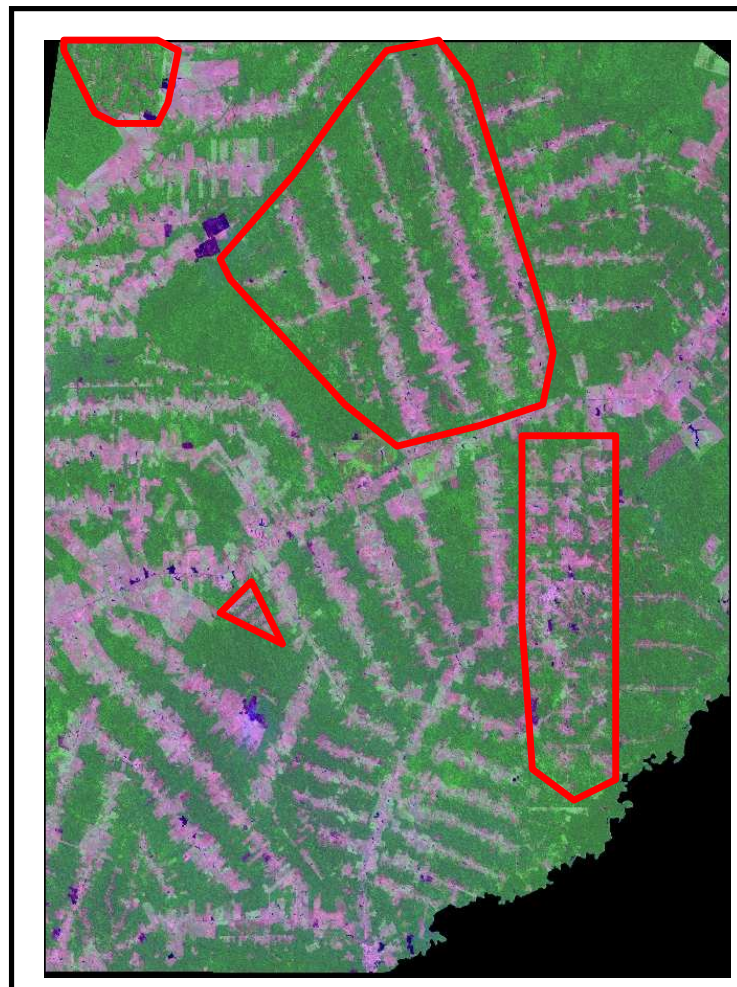

A

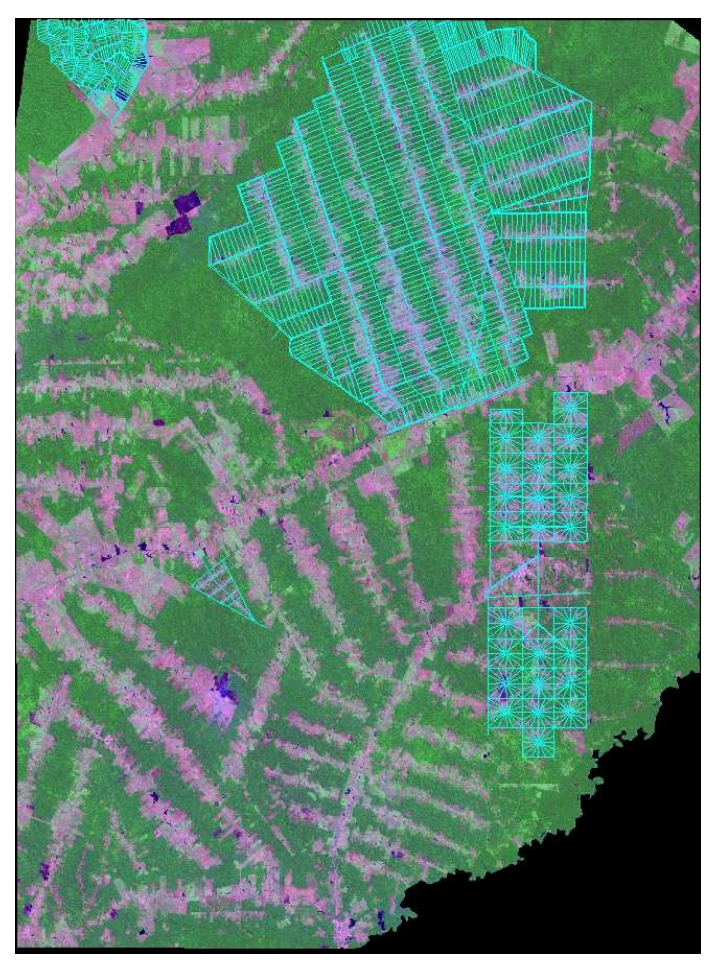

B

Figure 2 - a) Image with selected deforestations patterns, and b) Image with the settlement plan overlaid.

The next step was a field survey where the main task was to interview a sample of households selected to represent each spatial pattern identified in the previous step. The interview was based on a socio-economic questionnaire with the objective to identify the main socio-demographic and economic characteristic of households.

A statistical analysis of these data was aimed at finding a relation between spatial patterns of deforestation and land use as revealed by the household survey. Households with similar sociodemographic, economic, and land use characteristics were grouped based on cluster analysis. In this analysis, observations are clustered by computing the similarity between any pair of observation though a distance coefficient (Sokal, 1977). Two methods are usually used to group similar land use types or farming systems: K-means cluster analysis and hierarchical cluster analysis (Lesschen et al. 2005). We used the K-means clustering technique. It identifies relatively homogeneous groups of cases based on selected characteristics, using an algorithm that can handle large numbers of cases. In this procedure, the variables must be quantitative, and homogeneous in terms of scale. Distances between observations in the feature space are computed using a simple Euclidian distance (Lesschen et al. 2005). The procedure requires a prior selection of the appropriate number of clusters and inclusion of all relevant variables. A total of 12 initial clusters were defined to strike a trade-off between parsimony and within-group homogeneity. To further reduce the number of clusters, it was applied in two stages: after a first clustering based on land use data (acreage under cultivation and pasture, cropping system, livestock, crop production), the clusters with the highest frequency were isolated and only their observations reclustered using the same clustering procedure. The final clusters were georeferenced and overlaid on the land cover maps. 


\section{4 - Results and Discussion}

Maps of land-cover change were produced for 11 pairs of images from successive years: 199091, 1991-94, 1994-95, 1995-96, 1996-97, 1997-98, 1998-99, 1999-2001, 2001-02, 2002-03 and 2003-04. Four spatial patterns of land use were identified. Rates of deforestation were estimated for the entire study area and for each pattern. A total of 118 socio-economic questionnaires were administered and 43 points observed in the field and georeferenced by GPS.

\section{1 - Identification of the deforestation patterns}

The study area is one of the larger and older settlement in the Brazilian Amazon. This settlement started in the 1970s. Each of the four spatial pattern of land use identified was started in a different period, based on a different land use plan (Figure 3 ).

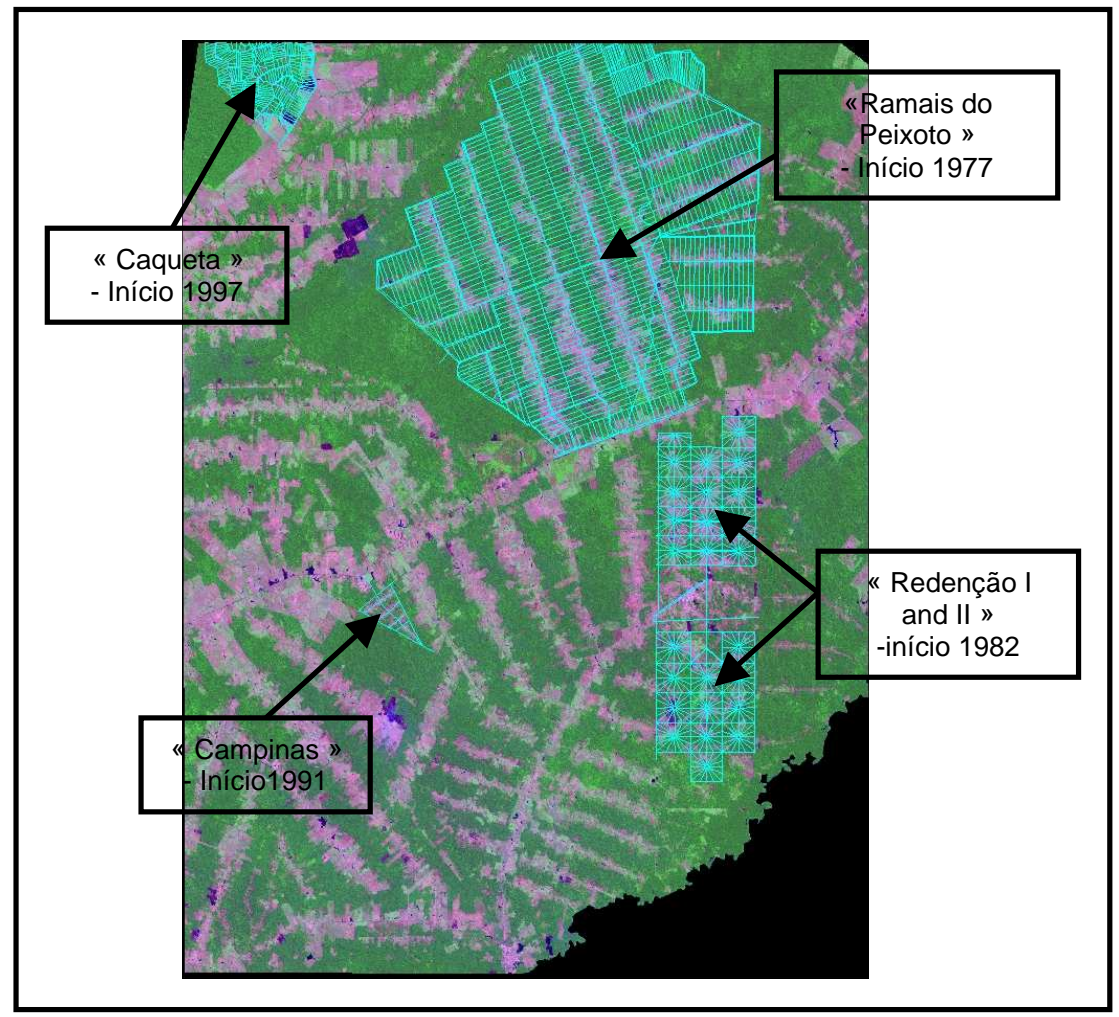

Figure 3 - Selected spatial patterns of land use in the study area.

\subsection{1 - Ramais do Peixoto (1977)}

The settlement project "Pedro Peixoto" was implemented in 1977 with a standard conception of land use: farms with an area from 80 to 100 ha distributed alongside parallel roads, perpendiculars to a main road. This land use plan was known as "fishbone". The main activity is extensive ranching of cattle.

\subsection{2 - Redenção 1 and 2 (1982)}

In 1982 the Institute of Colonization implemented a new conception of land use based on an Israeli conception aimed at stimulating social contacts between inhabitants of the area. In this planning, the farms with an area of about 80 ha are disposed in a radial form inside a square with a common area at the center of the square . 


\subsection{3 - Campinas (1991)}

The Campinas project was conceived to concentrate a large number of families in a relatively small area. The individual landholdings are only 4 ha and are dedicated to small-scale family cultivation, fruit production, and small livestock. Depending on the property size, the producers have the permission to clear all the forest on the property.

\subsection{4 - Caqueta (1997)}

The actual conception of colonization projects in Amazon tries to integrate families and forest as a way to diminish the impact on the forest caused by the presence of colonists. In the Caqueta project, the landholdings vary from 15 to 25 ha. It was conceived to respect the old "seringal" roads and the inhabitants were stimulated to adopt old land uses less aggressive to forest, such as rubber extraction.

\section{2 - Deforestation in the occupation patterns}

Despite the difference in occupation date and in the size of landholdings, the analysis of deforestation for each occupation pattern in the study period demonstrated that the proportion of forest loss was approximately the same for each spatial pattern of land use. It is highest for Caqueta, even though it was designed to minimize deforestation. This can be related to inappropriate land use policies or financial support that do not take into account the differences in colonization projects and their concepts. Figure 4 shows the proportion of forest lost for each spatial pattern of land use.

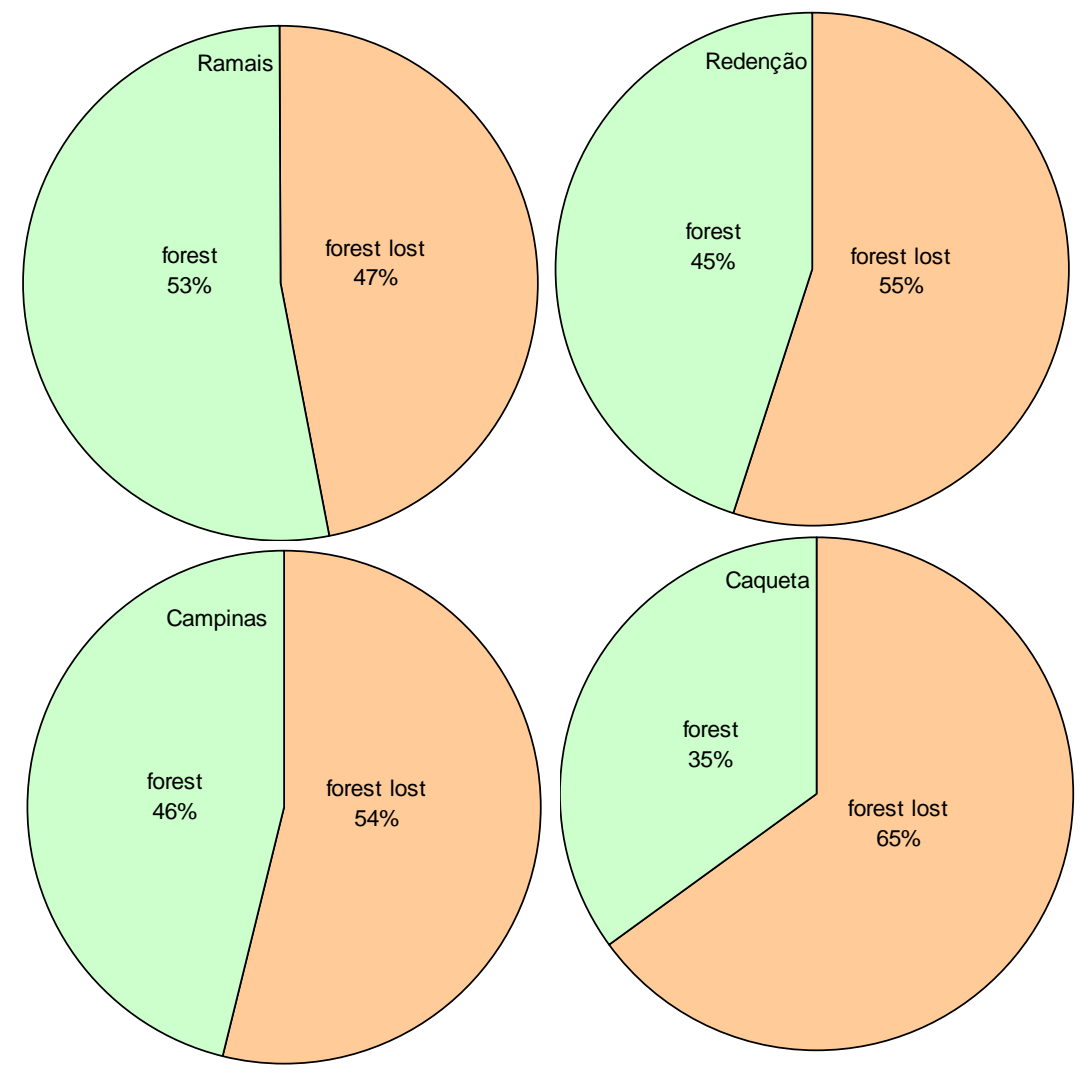

Figure 4 - Proportion of forest lost for each spatial pattern of land use. 
On a plot of deforestation for each spatial pattern of land use (Figure 5), it can be observed that the decline in forest area as a function of the increase in non-forest area are similar across all four sites per year corresponding to a same national or regional policy.

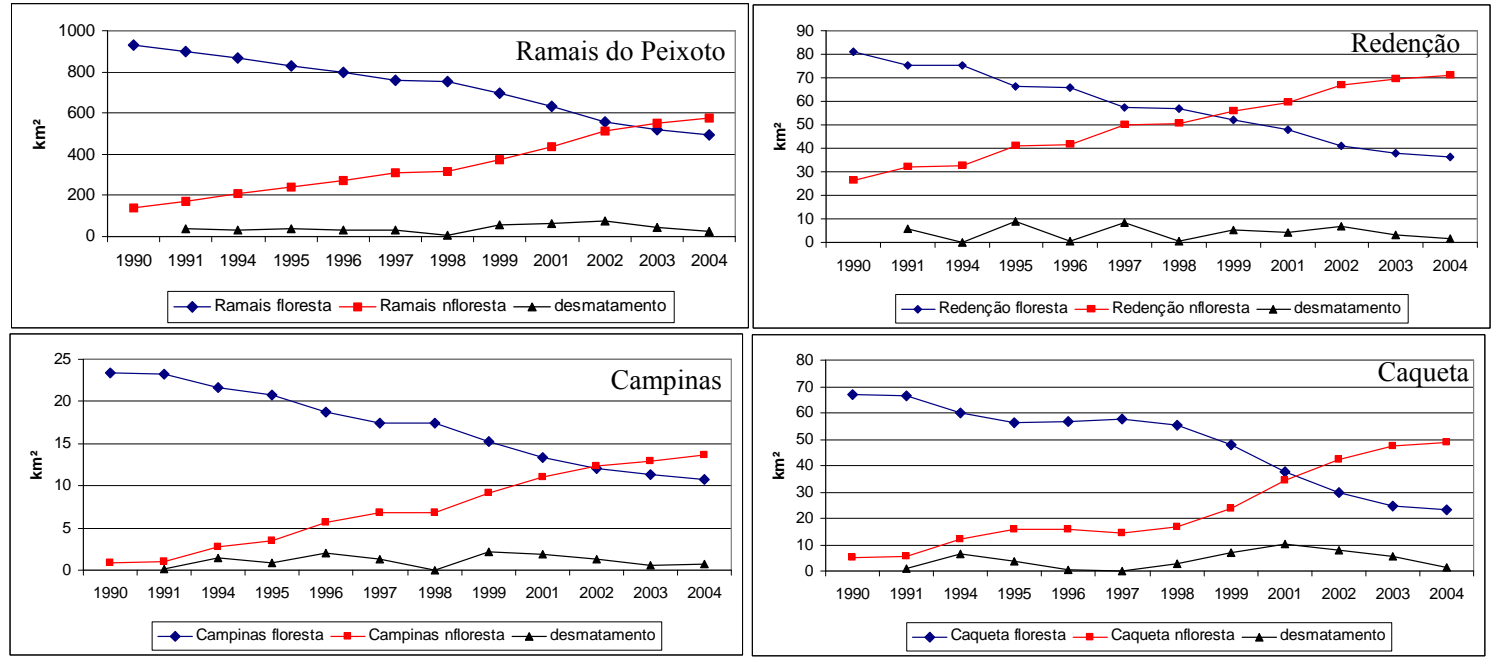

Figure 5 - Deforestation in each occupation pattern

\section{3 - Cluster analysis}

The cluster analysis based on land use data, independent from the total size and location of landholdings, generated two high frequency clusters (figure 6): cluster 9 with 16 households and cluster 10 with 89 households. Farms in cluster 9 are characterized by a large number of cattle and large pasture areas. It largely corresponds to the spatial patterns of land use 1 (Ramais) and 2 (Redenção), with landholdings around 80 to 100 ha and large areas allocated to pasture. The cluster 10 was formed by $75 \%$ of households associated with all spatial patterns of land use, with common characteristics related to cattle and cultivation.
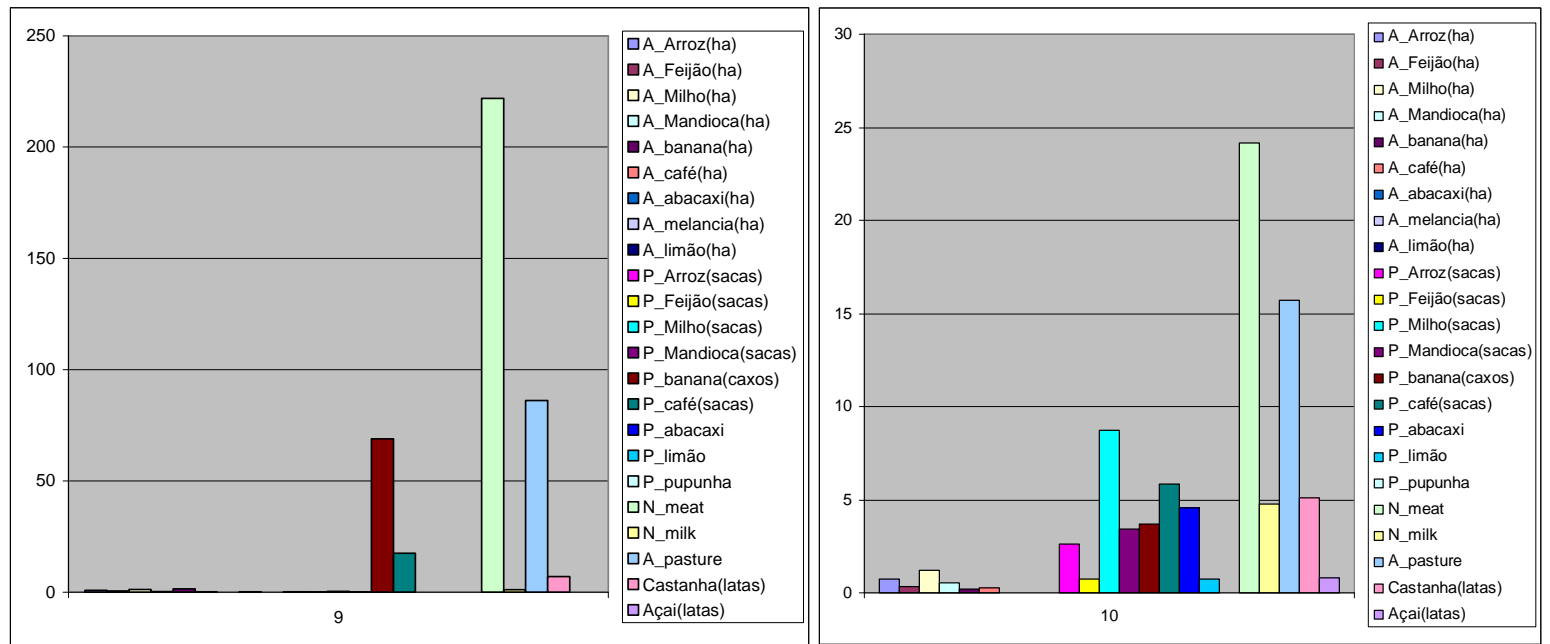

Figure 6 - Clusters 9 and 10

This cluster 10 includes more than half of the households interviewed and covers more or less all land use activities investigated. This could indicates either that: (1) land use activities occur in equal way in each spatial pattern and there are no relation between deforestation pattern and land use activities; everybody makes a bit of everything to survive without any clearly differentiated 
land use strategy; or (2) each indicator of land use activity is related to a specific pattern showing that specific spatial patterns of land use are related specific land use strategies. To test this, the households that were part of cluster 10 were isolated and reclustered using the same procedure. This second procedure concerning only cluster 10 produced 4 new significant clusters with $80 \%$ of the households (Figure 7). In this case, each cluster is clearly related to a specific land use activity.
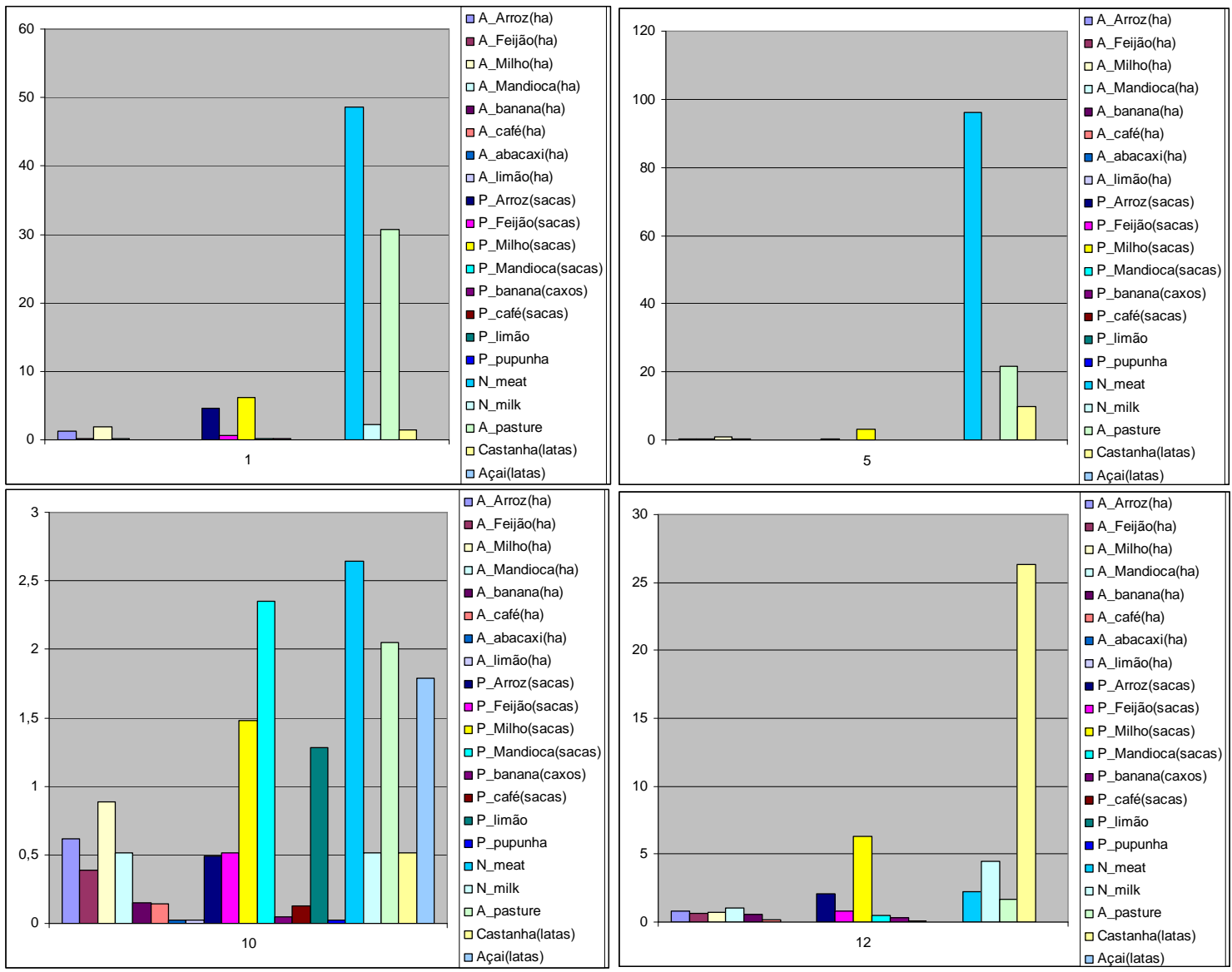

Figure 7 - Four more significant clusters from the reclustering of cluster 10

The first two clusters, respectively 1 and 5, are mainly related to cattle activities. This can be seen in the number of animals and in the area dedicated to pasture (Figure 7). Cluster 1 is formed at $80 \%$ by households from the spatial patterns of land use 1 and 2 , and $90 \%$ of the cluster 5 is formed by households from the spatial pattern of land use 1. The two occupation patterns were historically destined for cattle activities. The characteristics of the two other clusters are mainly related to small-scale cultivation and forest extraction activities. This is noted in cluster 10 for example, by the presence and area of cultivation computed to the number of animals and area of pasture, and in cluster 12 by the strong component of forest extraction products. Households from cluster 10 are more focused on the small production of fruits, flours, and subsistence crops, corresponding for $80 \%$ of the households to the spatial patterns of land use 3 and 4 (50\% from 3 and $30 \%$ from 4 ). Cluster 12 is formed by $80 \%$ of households from the spatial pattern of land use 4. The spatial pattern of land use 3 was meant to be mainly concentrated on the production of fruits, small animals, and subsistence crops, and the spatial patterns of land use 4 was conceived 
to stimulate the extraction of non-timber forest products such as rubber and "castanha" (chestnut).

\section{5 - Conclusion}

The results obtained by this study demonstrated that spatial patterns of deforestation as visualized by satellite images are related to land use data as collected by household survey. This linkage will allow for a better understanding of the dynamic of land use and cover change at a regional scale. Although the different spatial patterns of land use are characterized by similar rates of deforestation and proportions of forest lost, the statistical analysis showed that each deforestation pattern is associated with specific land use activities. The similar rates of deforestation come from the fact that the different spatial patterns of land use analyzed here are all part of the same large settlement project and are affected by the same policy, macroeconomic, and accessibility factors, independent of the local-scale land use strategies.

This study using satellite images, field survey data, and cluster analysis contributed to land change studies exploring the linkage between remote sensing data and field survey data ("people-to-pixels"). Next steps will include a more detailed statistical investigation of the socioeconomic data and deforestation data at the level of individual household or landholding. Testing of this linkage to other regions should also be conducted.

\section{6 - Bibliography}

Duarte, V; Shimabukuro, Y E; dos Santos,J. R.; Mello, E. M. K.; Moreira; J. C.; Moreira, M. A.; de Souza, R. C. M.;Shimabukuru, R. M. K; de Freitas, U. M Metodologia para criação do Prodes digital e do banco de dados digitais da Amazônia- Projeto Baddam. São José dos Campos: INPE, 33 p. (INPE-7032- PUD/035), 1999.

Lesschen, Jan Peter ; Verburg, Peter H. ; Staal, Steven J. Statistical Methods for analysing the spatial dimension of changes in land use and farming systems. LUCC Report Serie 7, International Livaestosk Research Institute, Nairobi - Kenia and LUCC Focus 3 Office, Wageningen University, the Netherlands, 2005

Rindfuss R.R., Stern P.C. Linking Remote Sensing and Social Science: The Need and the Challenges. In Liverman, D., Moran, E.F., Rindfuss R.R People and Pixel: Linking Remote Sensing and Social Science. National Academic Press, 1 - 27, 1998.

Sokal R.R. 1977. Clustering and classification: Background and current directions. In: van Ryzin J. (ed), Classification and clustering: Proceedings of an advanced seminar conducted by the Mathematics Research Centre. University of Wisconsin, Madison, USA

Veneziani, P; Métodos de extração visual de dados. São José dos Campos: INPE, 58 p., 1984. 